\title{
Who is going to walk? A review of the factors influencing walking recovery after spinal cord injury
}

\author{
Giorgio Scivoletto $^{1,2}{ }^{*}$, Federica Tamburella ${ }^{1,2}$, Letizia Laurenza ${ }^{1}$, Monica Torre ${ }^{1}$ and Marco Molinari ${ }^{1,2}$ \\ Spinal Cord Unit, IRCCS Fondazione S. Lucia, Rome, Italy \\ ${ }^{2}$ Clinical and Research Movement Analysis Lab, Fondazione S. Lucia, Rome, Italy
}

\author{
Edited by: \\ Nadia Dominici, Swiss Federal \\ Institute of Technology in Lausanne, \\ Switzerland \\ Reviewed by: \\ John Francis Ditunno, Thomas \\ Jefferson University, USA \\ Armin E. P. Curt, University Hospital \\ Balgrist, Switzerland \\ Kristin Musselman, University of \\ Saskatchewan, Canada \\ ${ }^{*}$ Correspondence: \\ Giorgio Scivoletto, Spinal Cord Unit, \\ IRCCS Fondazione S. Lucia, Via \\ Ardeatina 306, 00179 Rome, Italy \\ e-mail:g.scivoletto@hsantalucia.it
}

The recovery of walking function is considered of extreme relevance both by patients and physicians. Consequently, in the recent years, recovery of locomotion become a major objective of new pharmacological and rehabilitative interventions. In the last decade, several pharmacological treatment and rehabilitative approaches have been initiated to enhance locomotion capacity of $\mathrm{SCl}$ patients. Basic science advances in regeneration of the central nervous system hold promise of further neurological and functional recovery to be studied in clinical trials. Therefore, a precise knowledge of the natural course of walking recovery after $\mathrm{SCl}$ and of the factors affecting the prognosis for recovery has become mandatory. In the present work we reviewed the prognostic factors for walking recovery, with particular attention paid to the clinical ones (neurological examination at admission, age, etiology gender, time course of recovery). The prognostic value of some instrumental examinations has also been reviewed. Based on these factors we suggest that a reliable prognosis for walking recovery is possible. Instrumental examinations, in particular evoked potentials could be useful to improve the prognosis.

Keywords: spinal cord injury, walking recovery, prognostic factors

\section{INTRODUCTION}

Walking recovery is one of the main goals of patients after SCI: walking is rated at first place (together with bladder and bowel function) at least by patients with incomplete lesions (Ditunno et al., 2008a). Furthermore, an epidemiological study shows an increase of the number of patients with incomplete lesions (e.g., with chances of walking recovery) (Pagliacci et al., 2003). Therefore, the recovery of ambulation has become the target of several pharmacological and rehabilitative approaches (Wernig and Muller, 1992; Domingo et al., 2012) and a precise evaluation of the natural recovery of walking and of the prognostic factors influencing this function has become mandatory (Steeves et al., 2007).

In the present work we reviewed the effect of several clinical and demographic features on the prognosis for walking recovery. Furthermore, because one of the main problems of the acute phase of SCI is the lack of reliable examinations, we considered the prognostic value of neurophysiological and neuroimaging examinations.

Finally, the effect of early pharmacological and surgical interventions on walking recovery will be examined.

\section{MATERIALS AND METHODS}

A systematic search was performed of all papers as well as websites mentioning spinal cord injury and walking The literature search was conducted without time limits to identify papers that explicitly mentioned the walking capacity in patients with SCI. Databases included PubMed, Ovid MEDLINE, CINAHL, PsychINFO, Cochrane Central Register of Controlled Trials and Scopus, which includes Embase citations. All study designs, including case reports, were included, with no restrictions on the ages of participants. Non-English articles and animal studies were excluded. The following search terms were used: prognosis prediction, SCI, paraplegia/tetraplegia/quadriplegia, ambulation/gait and walking/walking capacity. In addition, other databases, such as Google and a hand search of Spinal Cord yielded other citations not identified by the above strategy.

Two authors (Giorgio Scivoletto and Federica Tamburella) independently identified and classified the papers through a review of the abstracts, texts, and references and circulated them to the authors' panel.

\section{CLINICAL EXAMINATION}

The most relevant prognostic factor for functional recovery in SCI patients is the neurological status at the moment of the first examination. The physical examination of these patients has been standardized by the American Spinal Injury Association in the International Standards for Neurological Classification of Spinal Cord Injury (ISNCSCI) (American Spinal Injury Association, 2000). Based on this examination it is possible to establish the neurological level of injury, as well as the severity of the lesion (impairment). Components also include a rectal examination for voluntary anal contraction and anal sensation (Figures 1, 2). Patients are considered to have a complete lesion (AIS impairment A), according to the ASIA Impairment Scale (AIS), in the absence of sensory or motor function at the lowest sacral segments. Incomplete lesions are defined when sensation and/or motor function are preserved below the neurologic level of injury, and in particular in the lowest sacral segments (anal sensation, including deep anal pressure and voluntary external anal sphincter contraction) (Figure 2). 


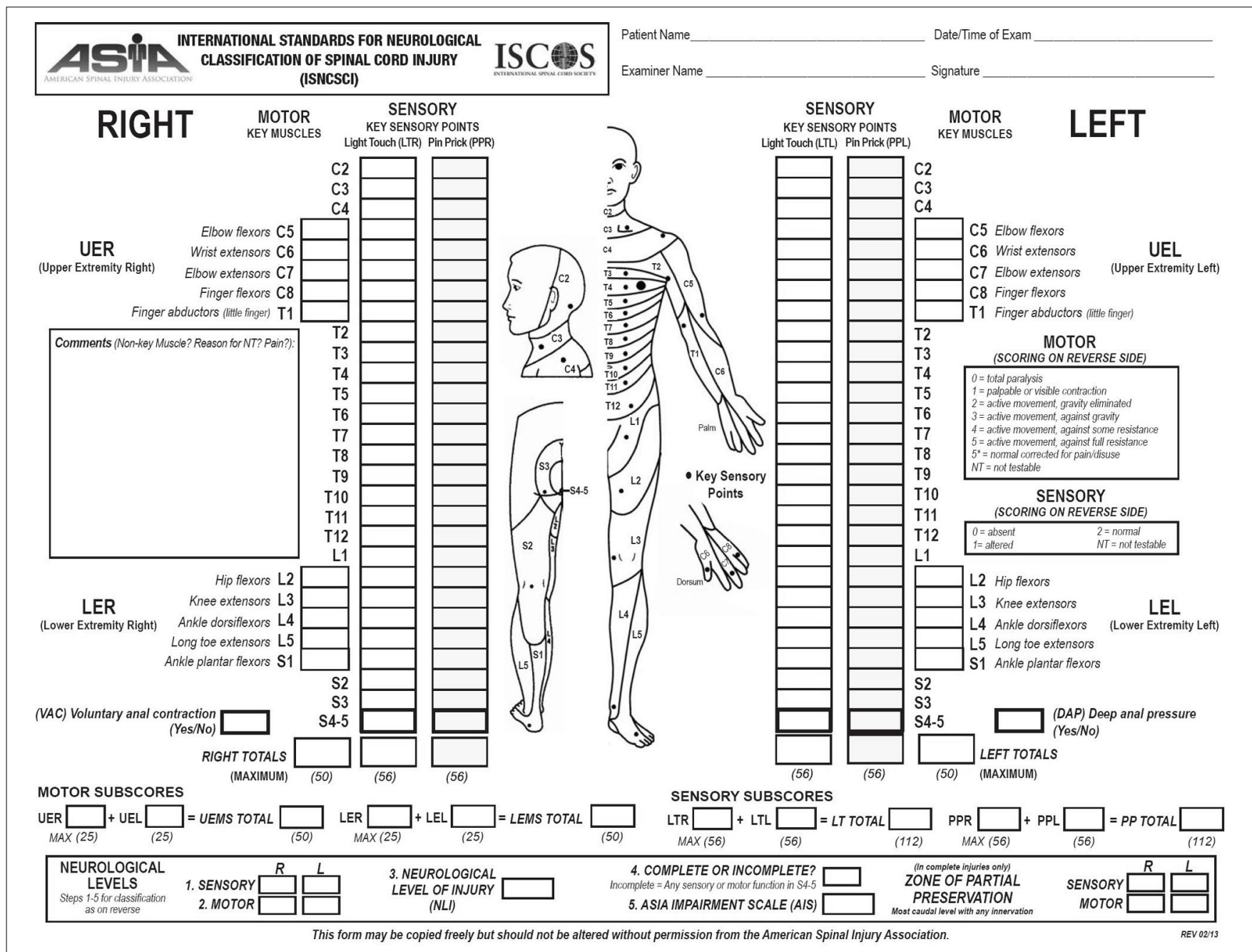

FIGURE 1 | Scoring sheet for the International Standards for Neurological Classification of Spinal Cord Injury. American Spinal Injury Association: International Standards for Neurological Classification of Spinal Cord Injury, revised 2013; Atlanta, GA. Reprinted 2013.

This examination should usually be performed at $72 \mathrm{~h}$ after the lesion because this timing seems to have a more accurate prognostic value than earlier assessment (Herbison et al., 1991).

\section{AIS GRADE CONVERSION AND WALKING RECOVERY}

For the aim of this review we would define walking recovery as the regained ability to walk independently in the community, with or without the use of devices and braces. This is also defined "functional walking" and has been described by several authors (Hussey and Stauffer, 1973) as the capacity to walk reasonable distances both in and out of home unassisted by another person.

For a long time AIS grade conversion has been considered the basis to predict the possibility of achieving functional walking. However, a recent article by van Middendorp et al. (2009) questioned the relationship between AIS grade conversion and ability to walk as we will show below.

Patients with AIS impairment A (motor and sensory complete lesion) at their first examination have very few chances of neurological recovery below the lesion. When the examination is performed at $72 \mathrm{~h}$ post-injury, $80 \%$ of the initial AIS A patients remain as AIS A, with about $10 \%$ converting to AIS B (i.e., some sensory function) and about $10 \%$ converting to AIS C (with some motor recovery below the lesion) (Burns et al., 2012). However, if the first examination is performed later, the percentage of improvement decreases dramatically to $2.5 \%$ (Scivoletto et al., 2004a) (Table 1). Accordingly, the possibility of patients with AIS impairment $\mathrm{A}$ of achieving functional walking is very limited too. Furthermore, also between the patients who converted to an incomplete lesion only $14 \%$ recovered some walking function (van Middendorp et al., 2009). The AIS A patients who achieve some walking function usually are low thoracic or lumbar levels (T12-L3) and need braces and devices to walk (Ditunno et al., 2008b; Table 2). Finally, these patients are usually limited ambulators, with slow average velocities and great energy expenditure (Vaccaro et al., 1997).

AIS grade B patients (those with motor complete, sensory incomplete lesion at $72 \mathrm{~h}$ examination) usually show some motor recovery and they can convert to AIS C or even AIS D grade. However, the overall recovery of ambulation is considered to be about 33\% (Katoh and el Masry, 1995; van Middendorp et al., 


\begin{tabular}{|c|c|c|}
\hline \multicolumn{2}{|l|}{ Muscle Function Grading } & ASIA Impairment Scale (AIS) \\
\hline \multicolumn{2}{|l|}{$\mathbf{0}=$ total paralysis } & \\
\hline \multicolumn{2}{|l|}{$\mathbf{1}=$ palpable or visible contraction } & $A=$ Complete. No sensory or motor function is preserved in \\
\hline \multicolumn{2}{|c|}{2 = active movement, full range of motion ( $R O M$ ) with gravity eliminated } & \\
\hline \multicolumn{2}{|c|}{$\mathbf{3}$ = active movement, full ROM against gravity } & B = Sensory Incomplete. Sensory but not motor function \\
\hline \multicolumn{2}{|c|}{$\begin{array}{l}\mathbf{4} \text { = active movement, full ROM against gravity and moderate resistance in a muscle } \\
\text { specific position. }\end{array}$} & $\begin{array}{l}\text { is preserved below the neurological level and includes the sacral } \\
\text { segments } S 4-5 \text { (light touch or pin prick at } S 4-5 \text { or deep anal }\end{array}$ \\
\hline \multicolumn{2}{|c|}{$\begin{array}{l}\mathbf{5} \text { = (normal) active movement, full ROM against gravity and full resistance in a } \\
\text { functional muscle position expected from an otherwise unimpared person. }\end{array}$} & $\begin{array}{l}\text { pressure) AND no motor function is preserved more than three } \\
\text { levels below the motor level on either side of the body. }\end{array}$ \\
\hline \multicolumn{2}{|c|}{$\begin{array}{l}\mathbf{5}^{*}=\text { (normal) active movement, full ROM against gravity and sufficient resistance to be } \\
\text { considered normal if identified inhibiting factors (i.e. pain, disuse) were not present. }\end{array}$} & $\begin{array}{l}\mathrm{C}=\text { Motor Incomplete. Motor function is preserved below } \\
\text { the neurological level**, and more than half of key muscle }\end{array}$ \\
\hline \multicolumn{2}{|c|}{$\begin{array}{l}\text { NT = not testable (i.e. due to immobilization, severe pain such that the patient cannot } \\
\text { be graded, amputation of limb, or contracture of }>50 \% \text { of the normal range of motion). }\end{array}$} & $\begin{array}{l}\text { functions below the neurological level of injury (NLI) have a } \\
\text { muscle grade less than } 3 \text { (Grades } 0-2 \text { ). }\end{array}$ \\
\hline \multicolumn{2}{|l|}{ Sensory Grading } & $\mathrm{D}=$ Motor Incomplete. Motor function is preserved below \\
\hline & $\begin{array}{l}\text { the neurological level*, and at least half (half or more) of key } \\
\text { muscle functions below the NLI have a muscle grade } \geq 3 \text {. }\end{array}$ \\
\hline \multirow{2}{*}{\multicolumn{2}{|c|}{$\begin{array}{l}\mathbf{2}=\text { Normal } \\
\text { NT }=\text { Not testable }\end{array}$}} & $\mathrm{E}=$ Normal. If sensation and motor function as tested with the \\
\hline & & $\begin{array}{l}\text { ISNCSCI are graded as normal in all segments, and the patient } \\
\text { had prior deficits, then the AIS grade is E. Someone without an }\end{array}$ \\
\hline \multicolumn{2}{|c|}{ Non Key Muscle Functions (optional) } & initial SCl does not receive an AlS grade. \\
\hline \multicolumn{2}{|c|}{ May be used to assign a motor level to differentiate AIS B vs. C } & ** For an individual to receive a grade of $\mathrm{C}$ or D, i.e. motor incomplete \\
\hline Movement & Root level & status, they must have either (1) voluntary anal sphincter contraction or \\
\hline $\begin{array}{l}\text { Shoulder: Flexion, extension, abduction, adduction, internal } \\
\text { and extemal rotation } \\
\text { Elbow: Supination }\end{array}$ & C5 & $\begin{array}{l}\text { levels below the motor level for that side of the body. The International } \\
\text { Standards at this time allows even non-key muscle function more than } 3 \\
\text { levels below the motor level to be used in determining motor incomplete }\end{array}$ \\
\hline $\begin{array}{l}\text { Elbow: Pronation } \\
\text { Wrist: Flexion }\end{array}$ & C6 & $\begin{array}{l}\text { status (AS B versus C). } \\
\text { NOTE: When assessing the extent of motor sparing below the level }\end{array}$ \\
\hline $\begin{array}{l}\text { Finger: Flexion at proximal joint, extension. } \\
\text { Thumb: Flexion, extension and abduction in plane of thumb }\end{array}$ & C7 & $\begin{array}{l}\text { for distingushing between AIS B and C, the motor level on each } \\
\text { side is used; whereas to differentiate between AIS C and D (based on } \\
\text { proportion of key muscle functions with strength grade } 3 \text { or greater) the }\end{array}$ \\
\hline $\begin{array}{l}\text { Finger: Flexion at MCP joint } \\
\text { Thumb: Opposition, adduction and abduction perpendicula }\end{array}$ & C8 & neurological level of injury is used. \\
\hline
\end{tabular}

Thumb: Opposition, adduction and abduction perpendicular

to palm

Finger: Abduction of the index finge

Hip: Adduction

Hip: Extemal rotation

Hip: Extension, abduction, intemal rotation

Knee: Flexion

Ankle: Inversion and eversion

Toe: MP and IP extension

Hallux and Toe: DIP and PP flexion and abduction

Hallux: Adduction

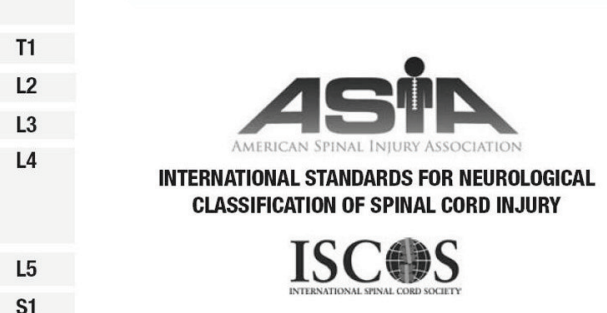

\section{Steps in Classification \\ The following order is recommended for determining the classification of individuals with SCI. \\ 1. Determine sensory levels for right and left sides. The sensory level is the most caudal, intact dermatome for both pin prick and light touch sersation. \\ 2. Determine motor levels for right and left sides. \\ Defined by the lowest key muscle function that has a grade of at least 3 (on supine testing), providing the key muscle functions represented by segments above that level are judged to be intact (graded as a 5). \\ Note: in regions where there is no myotome to test, the motor level is \\ presumed to be the same as the sensory level, if testable motor function above that level is also nomal. \\ 3. Determine the neurological level of injury (NLI) \\ This refers to the most caudal segment of the cord with intact sensation and antigravity ( 3 or more) musde function strength, provided that there is normal (intact) sensory and motor function rostrally respectively. \\ The NLI is the most cephalad of the sensory and motor levels determined in steos 1 and 2 \\ 4. Determine whether the injury is Complete or Incomplete. (i.e. absence or presence of sacral sparing) \\ If voluntary anal contraction $=$ No AND all S4-5 sensory scores $=0$ \\ AND deep anal pressure $=$ No, then iniurv is Complete. \\ Otherwise, iniury is Incomplete. \\ 5. Determine ASIA Impairment Scale (AIS) Grade: \\ Is injury Complete? If YES, AIS=A and can record \\ No $\quad$ ZPP each side with some presenvation \\ Is injury Motor Complete? If YES, AIS=B \\ NO (No=voluntary anal contraction OR motor function more than three levels below the motor level on given side, if the patient has sensory incomplete classification)}

Are at least half (half or more) of the key muscles below the neurological level of injury graded 3 or better?

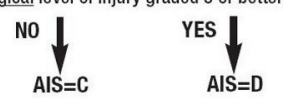

If sensation and motor function is normal in all segments, AIS=E Note: AIS E is used in follow-up testing when an individual with a documented SCI has recovered normal function. If at initial testing no deficits are found, the individual is neurologically intact; the ASIA Impairment Scale does not apply.

FIGURE 2 | Scoring sheet for the International Standards for Neurological Classification of Spinal Cord Injury. American Spinal Injury Association: International Standards for Neurological Classification of Spinal Cord Injury, revised 2013; Atlanta, GA. Reprinted 2013.

Table 1 | Prediction of recovery according to AIS impairment scale.

\begin{tabular}{lcccc}
\hline AIS grade at admission & A & B & C & D \\
\hline First examination at $\mathbf{7 2} \mathbf{h}^{\mathbf{1 0}}$ & \multicolumn{4}{c}{ One-year follow-up AIS grade } \\
\hline A & $84 \%$ & $8 \%$ & $5 \%$ & $3 \%$ \\
B & $10 \%$ & $30 \%$ & $29 \%$ & $31 \%$ \\
C & $2 \%$ & $2 \%$ & $25 \%$ & $67 \%$ \\
D & $2 \%$ & $1 \%$ & $2 \%$ & $85 \%$ \\
\hline
\end{tabular}

First examination at 30 days $^{11}$ One-year follow-up AIS grade

\begin{tabular}{ccccc}
\hline A & $95 \%$ & 0 & $2,5 \%$ & $2,5 \%$ \\
B & 0 & $53 \%$ & $21 \%$ & $26 \%$ \\
C & $1 \%$ & 0 & $45 \%$ & $54 \%$ \\
D & $2 \%$ & 0 & 0 & $96 \%$ \\
\hline
\end{tabular}

2009). The percentage of walking recovery may vary depending on the modality of the sensation spared at the lowest sacral segments. Several studies reported a relationship between pinprick preservation and recovery in AIS B patients. AIS grade B patients with pinprick preservation have a better walking recovery than those with light touch only (Foo et al., 1981; Crozier et al., 1991; Waters et al., 1994a; Katoh and el Masry, 1995; Oleson et al., 2005) (Table 2). This finding has an anatomical basis at the spinal cord level. The preservation of pinprick perception together with light touch one indicates less extensive damage to the spino-thalamic tracts and posterior column. Therefore, in these cases, there is a high likelihood of some sparing of the motor pathways conveyed by the nearby cortico-spinal tracts (Oleson et al., 2005).

Motor incomplete (AIS C) patients have a better prognosis for walking recovery than sensory incomplete ones. The overall rate of recovery is about 75\% (Maynard et al., 1979; Crozier et al., 1992; Waters et al., 1994b; van Middendorp et al., 2009). This percentage includes both the patients who converted to AIS D and those who remained AIS C but achieve at least some walking function (van Middendorp et al., 2009); these patients probably have low thoracic or lumbar lesions and walk with braces and devices. Several factors may influence the chance of walking recovery in these patients: lower extremity strength, motor recovery timing, age and upper extremity strength for tetraplegic patients are the 
Table 2 | Prediction of functional walking according to AIS impairment and other features.

\begin{tabular}{|c|c|}
\hline $\begin{array}{l}\text { AIS/lesion level } \\
\text { at admission }\end{array}$ & $\begin{array}{l}\text { Functional walking/ } \\
\text { authors (references) }\end{array}$ \\
\hline AIS A/cervical lesion & $\begin{array}{l}\text { 0\% (Waters et al., 1994a,b) } \\
\text { 0\% (Ditunno et al., 2008b) }\end{array}$ \\
\hline $\begin{array}{l}\text { AIS A/thoracic and } \\
\text { lumbar lesions }\end{array}$ & $\begin{array}{l}\text { 5\% (Waters et al., 1994a,b) } \\
\text { 8.5\% (Ditunno et al., 2008b) }\end{array}$ \\
\hline $\begin{array}{l}\text { AIS at admission } \\
\text { and sensation }\end{array}$ & $\begin{array}{l}\% \text { recovery of community } \\
\text { ambulation at } 1 \text { year post- } \\
\text { injury/authors (references) }\end{array}$ \\
\hline $\begin{array}{l}\text { AIS B (only light touch } \\
\text { preservation) }\end{array}$ & $\begin{array}{l}\text { 0\% (Waters et al., 1994a,b) } \\
\text { 11\% (Crozier et al., 1991) } \\
\text { 33\% (Waters et al., 1994a,b) }\end{array}$ \\
\hline $\begin{array}{l}\text { AIS B (light touch + pin } \\
\text { prick preservation) }\end{array}$ & $\begin{array}{l}\text { 89\% (Crozier et al., 1991) } \\
66 \% \text { (Foo et al., 1981) } \\
75 \% \text { (Katoh and el Masry, 1995) }\end{array}$ \\
\hline $\begin{array}{l}\text { AIS at admission } \\
\text { and age }\end{array}$ & $\begin{array}{l}\% \text { recovery of community } \\
\text { ambulation at } 1 \text { year post- } \\
\text { injury/authors (references) }\end{array}$ \\
\hline AIS $C<50$ years & $\begin{array}{l}91 \% \text { (Burns et al., 1997) } \\
71 \% \text { (Scivoletto et al., 2003) }\end{array}$ \\
\hline AIS C > 50 years & $\begin{array}{l}42 \% \text { (Burns et al., 1997) } \\
25 \% \text { (Scivoletto et al., 2003) }\end{array}$ \\
\hline AIS $D<50$ years & $\begin{array}{l}\text { 100\% (Burns et al., 1997) } \\
100 \% \text { (Scivoletto et al., 2003) }\end{array}$ \\
\hline AIS D > 50 years & $\begin{array}{l}\text { 100\% (Burns et al., 1997) } \\
80 \% \text { (Scivoletto et al., 2003) }\end{array}$ \\
\hline
\end{tabular}

most important ones (Crozier et al., 1992; Waters et al., 1994b). In AIS C patients age seems to be a strong prognostic factor for walking recovery. Age represents a clear negative prognostic factor for walking recovery: AIS C subjects younger than 50 years have a chance of achieving functional walking of $80-90 \%$, but this percentage dramatically decreases to $30-40 \%$ in older patients (Table 2) (Perot and Vera, 1982; Foo, 1986; Burns et al., 1997; Scivoletto et al., 2003). Different hypotheses have been offered to explain the negative effect of age. The functional potential for a given neurological deficit is lower at older age; this may be considered reasonable since functional abilities generally decline as people's age increases. In normal ageing "reserve (peak) capacity" (or "vitality") (DiGiovanna, 2000) seems to peak at around 30 years of age, and then gradually declines until death. Disease processes, including SCI and its complications, are considered to accelerate this process of decline. Jakob et al. (2009) offers another possible explanation. In his study he found that age is not correlated with neurologic recovery, but is correlated with a worse functional outcome in terms of independence in daily life activities and walking function. He therefore suggested that the neurological recovery is not directly related to the functional outcome and that elderly patients have difficulties in translating neurological recovery into positive functional changes.

Finally, AIS D patients at admission have very good ambulation prognosis at 1 year post-injury (Burns et al., 1997; Scivoletto et al., 2003). All patients, regardless of age, who initially were classified as AIS D (within $72 \mathrm{~h}$ ) were able to walk at the time of discharge from inpatient rehabilitation (Burns et al., 1997; van Middendorp et al., 2009).

\section{OTHER CLINICAL FACTORS}

In addition to AIS grade, several other factors evaluated at $72 \mathrm{~h}$ after the lesion have been considered in the prognosis of walking recovery and are examined below.

\section{REFLEXES}

In the very early examination of SCI patients the presence/absence of the delayed plantar response (DPR) must be assessed. DPR is characterized by a delayed response to an unusually strong stimulus to the sole of the foot (Weinstein et al., 1997). The onset of this response following the stimulus could be $500 \mathrm{~ms}$ or a full second following the initiation of the stimulus (Weinstein et al., 1997). The DPR shows a reciprocal relationship with the Babinski sign and it is particularly relevant because it allows the prognosis during the spinal shock phase (Ko et al., 1999). The DPR is a negative prognostic indicator as it is more often present and lasts longer (more than 1 day) in SCI patients who do not recover any voluntary movement (Weinstein et al., 1997; Ko et al., 1999).

\section{SYNDROMES}

Based on the distribution of sensory and motor loss, the ISNCSCI allow to identify several incomplete spinal cord syndromes with different prognostic values.

The central cord syndrome (CCS) is mostly seen following cervical lesion. It represents about $9 \%$ of the total SCIs and $44 \%$ of the clinical syndromes (Mckinley et al., 2007) and is characterized by a greater involvement of the upper extremities than the lower extremities. The CCS is a clinical picture that recognizes several causes (with and without bone injury) and several different mechanisms (including direct injury of the spinal cord or vascular injuries) (Mckinley et al., 2007) that primarily affects the center of the spinal cord and generally has a favorable prognosis as to independence in daily life activities and bladder and bowel function recovery (Newey et al., 2000; Dvorak et al., 2005; Aito et al., 2006). Because of the lesser involvement of the lower extremities, CCS is considered to have a good prognosis for walking recovery too (Merriam et al., 1986; Penrod et al., 1990; Roth et al., 1990; Burns et al., 1997; Aito et al., 2006). The percentage of patients who recover walking varies from 40 to $97 \%$, but is strongly influenced by age. Several studies confirm that younger patients (less than 50 years old) have twice the chance of achieving independent walking than older ones (Foo, 1986; Merriam et al., 1986; Penrod et al., 1990; Roth et al., 1990; Burns et al., 1997; Newey et al., 2000; Dvorak et al., 2005; Aito et al., 2006).

The Brown-Séquard syndrome (BSS) is characterized by ipsilateral hemiplegia and contralateral hemianalgesia due to spinal hemisection (Brown-Sequard, 1868). It accounts for $2-4 \%$ of all traumatic SCIs and $17 \%$ of the clinical syndromes (Mckinley et al., 2007). The pure form of BSS is rarely seen and the BrownSéquard Plus Syndrome (relative ipsilateral hemiplegia with a relative contralateral hemianalgesia) is much more frequent (Roth et al., 1991). BSS is more frequent at cervical level and is usually associated with stab-wound injuries (Gentleman and Harrington, 
1984). BSS is characterized by a good functional prognosis. About $75 \%$ of patients achieve independent walking at discharge from rehabilitation (Stahlman and Hanley, 1992). In this framework an important predictor for walking recovery is the distribution of the impairment: if the upper limb is weaker than the lower limb, then patients are more likely to ambulate at discharge (Kirshblum and O'Connor, 1998).

The anterior cord syndrome is due to a lesion that involves the anterior two thirds of the spinal cord and preserves the posterior columns (Maynard et al., 1997), and account for 1\% of all the SCIs and 5\% of the clinical syndromes (Mckinley et al., 2007). It may derive from a retropulsed disc or bone fragments (Bauer and Errico, 1991), direct injury to the anterior spinal cord, or with lesions of the anterior spinal artery that provides the blood supply to that tract of spinal cord (Cheshire et al., 1996). Lesions of the anterior spinal artery may result from diseases of the aorta, cardiac or aortic surgery, embolism, polyarteritis nodosa, or angioplasty (Cheshire et al., 1996). Anterior cord syndrome is characterized by a variable loss of motor as well as pinprick sensation with a relative preservation of light touch, proprioception, and deep-pressure sensation. Due to the massive involvement of the anterior and lateral spinal cord with inclusion of the corticospinal tracts, only $10-20 \%$ of the patients with an anterior cord syndrome have the chance to recover muscle function, and even in those with some recovery, usually motor strength is low and coordination is lacking; consequently these patients have low walking recovery chances (Bohlman, 1979).

\section{Etiology of the lesion}

Most of the literature on SCI is focused on the rehabilitation of traumatic patients, despite the relevant incidence of nontraumatic lesions, considered to account for a percentage of the total SCIs varying from 30 to $80 \%$ (Buchan et al., 1972; Celani et al., 2001; Citterio et al., 2004). Patients with nontraumatic lesions differ from their traumatic counterparts for several prognostic factors. They are usually older, with a more even distribution of genders and a higher frequency of incomplete lesions. Therefore, a direct comparison of these two populations is difficult (Scivoletto et al., 2011). However, when the confounding effect of these factors is eliminated by means of statistics, patients with non-traumatic spinal cord lesions can achieve comparable rates of functional gains as their traumatic spinal cord injury counterparts (Mckinley et al., 2000; McKinley et al., 2001; Mckinley et al., 2002). With regard to walking function, recently a number of articles compared the recovery of ambulation in traumatic and non-traumatic SCIs and found that the two populations achieve comparable walking capacity with an overall percentage of patients varying from 35 (Scivoletto et al., 2011) to $49 \%$ (Marinho et al., 2012).

\section{GENDER}

There are only few studies on gender related differences in neurological and functional outcomes after inpatient rehabilitation of SCI (Greenwald et al., 2001; Scivoletto et al., 2004b; Sipski et al., 2004). Two of them (Greenwald et al., 2001; Scivoletto et al., 2004b) found no significant differences between the two genders with regard to daily life independence, motor efficiency,
American Spinal Injury Association motor scores (Greenwald et al., 2001) and walking function (Scivoletto et al., 2004b). However, Sipski et al. (2004) found gender-related differences in daily life independence, but did not specifically focus on walking recovery. Women with SCI may have more natural neurologic recovery than men, but, for a given level and degree of neurologic injury, men tend to do better functionally than women at time of discharge from rehabilitation (Sipski et al., 2004).

\section{FORMULAS AND ALGORITHMS}

In the last three decades several attempts have been made to link one or more of the above mentioned factors (and of the results of instrumental examinations discussed below) to the prognosis for walking recovery.

Waters et al. (1994b) examined the relationship between lower extremity strength at first examination in incomplete paraplegics and walking recovery: all patients with an initial (1-month) lower extremity motor score of $\geq 10$ points ambulated in 1 year. Seventy percent of patients with an initial motor score between 1 and 9 ambulated at 1 year. Furthermore, all patients with an initial hip flexor or knee extensor Grade $\geq 2$ ambulated in the community at 1 year.

The same author examined the odds of walking recovery in incomplete tetraplegics and found that, although the relationship between initial lower extremity motor score and walking holds true for tetraplegics, these patients have less chance to achieve ambulation (Waters et al., 1994a): 63\% of the patients with an initial lower extremity motor score of $\geq 10$ points ambulated by 1 year, vs. $21 \%$ of those with an initial motor score between 1 and 9 (Waters et al., 1994a). In addition, Waters stressed the relationship between upper extremities strength and ambulation recovery in tetraplegics: patients who are community or household ambulators have significant higher motor scores. The author linked this datum to the importance of upper extremities strength for devices use during walking (Waters et al., 1994a).

Crozier et al. (1992) focused on the timing of recovery of lower extremity motor strength and concluded that early recovery of quadriceps strength is an excellent prognostic factor for ambulation. All patients with an initial quadriceps strength of at least Grade $2 / 5$ who attained a grade of $\geq 3 / 5$ in at least one quadriceps by 2 months post-injury achieved functional ambulation (ability to walk independently in the community, with or without the use of devices and braces) at follow-up. However, only $25 \%$ of those who did not recover quadriceps strength of $3 / 5$ within 2 months were able to walk at follow-up.

More recently, Zörner et al. (2010) developed an algorithm based on outcome predictors and aimed at identifying subgroups of patients in the sub-acute phase who could achieve functional walking. For patients with incomplete paraplegia, lower extremity motor scores, pinprick scores and age were the best predictors for walking recovery. For patients with incomplete tetraplegia the more reliable predictors were the lower extremity motor scores, the tibial SSEP score and the AIS grade.

In 2011 van Middendorp et al. (2011) produced a simple clinical prediction rule based on the combination of age $(<65$ vs. $\geq 65$ years), motor scores of the quadriceps femoris (L3), gastrocsoleus (S1) muscles, and light touch sensation of dermatomes 
L3 and S1. This rule showed an excellent discrimination capacity in recognizing patients who achieved independent ambulation (ability to walk independently, with or without braces and orthoses for $<10 \mathrm{~m}$ ) at follow-up from those who were dependent walkers or non-walkers.

\section{INSTRUMENTAL EXAMINATION}

\section{SOMATOSENSORY EVOKED POTENTIALS (SSEPs) (Table 3)}

SSEPs are used for clinical diagnosis in patients with neurologic disease, and many studies have been performed to determine the value of SSEPs in the prediction of walking recovery in SCI patients (Young and Dexter, 1979; Kaplan and Rosen, 1981; Young, 1985; Foo, 1986; Ziganow, 1986; Katz et al., 1991; Aalfs et al., 1993; Jacobs et al., 1995; Curt and Dietz, 1997).

Most of these studies conclude that early SSEPs can predict motor improvement and ambulation outcome in SCI patients. However, SSEPs do not seem to offer additional prognosticaccuracy if compared to clinical examination according to the ISNCSCI for both complete and incomplete patients (Young and Dexter, 1979; Kaplan and Rosen, 1981; Perot and Vera, 1982; Chabot et al., 1985; Katz et al., 1991; Aalfs et al., 1993; Curt and Dietz, 1997).

When a reliable clinical examination, together with the ISNCSCI is impossible (patients unresponsive, for example because sedated or under the effect of alcohol or drugs, or uncooperative, for example because of pain) then SSEPs are helpful to determine if they have SCI (Curt and Dietz, 1997). In addition, SSEPs may be helpful to differentiate between SCI and hysteric paraplegia, a differential diagnosis that may be very difficult (Kaplan et al., 1985).

\section{Motor Evoked Potentials (MEPs) (Table 3)}

Transcranial magnetic stimulation allows an examination of the conductivity of the motor tracts following cortical or spinal lesions in humans. According to a study of Curt, MEPs can contribute toward diagnosing lesions of different neurologic structures within the spinal cord and in predicting the recovery of functional movements (Curt et al., 1998). The study shows that MEPs recordings are sensitive to indicate motor tract lesions in

Table 3 | Prognostic value of SSEPs and MEPs.

\begin{tabular}{lccc}
\multicolumn{4}{c}{ Six months walking capacity } \\
\hline Normal & Functional & Therapeutic & No walking \\
$(\%)$ & $(\%)$ & $(\%)$ & function (\%)
\end{tabular}

LOWER LIMBS SSEPS AND AMBULATION (Curt and Dietz, 1997) Intial SSEP evaluation

\begin{tabular}{lcccc}
\hline Normal & 83 & 17 & 0 & 0 \\
Present, altered & 10 & 60 & 10 & 20 \\
Absent & 0 & 7 & 13 & 80 \\
\hline
\end{tabular}

LOWER LIMBS MEP AND AMBULATION (Curt et al., 1998) Intial MEP evaluation

\begin{tabular}{lcccc}
\hline Normal & 100 & 0 & 0 & 0 \\
Absent & 11 & 0 & 78 &
\end{tabular}

approximately $90 \%$ of SCI patients and predictive for the recovery of upper and lower limb motor function. In this sense they are of similar prognostic value to clinical examination in the prediction of functional recovery. MEPs can be used in combination with the ASIA protocol to follow the recovery of clinical motor functions in relation to that of descending motor tracts for impulse transmission. In Curt's study, MEPs were highly predictive of ambulatory capacity. All patients with elicitable MEPs at initial examination recovered a muscle strength of 3/5 or more of the respective muscles. Not surprisingly, MEPs recordings in SCI patients are more sensitive than SSEPs recordings for revealing the involvement of motor tract fibers and are at least as sensitive as the ASIA protocol in predicting the resulting functional deficit. Similarly to SSEPs, the use of MEP recordings is mostly appropriate in patients who are uncooperative (approximately $15 \%$ of patients with acute SCI) (Bozzo et al., 2011).

\section{Magnetic resonance imaging (Table 4)}

Before the advent of MRI, there were no imaging methods to assess the severity of traumatic SCI. MRI provides a rapid non-invasive means of evaluating the condition of spinal cord parenchyma and depicting the injured spinal cord and accurately showing the extent of macroscopic damage (Yamashita et al., 1991). It should be noted, however, that to the best of our knowledge, no study examined the relationship between MRI aspect and walking recovery, but only with neurologic recovery (AIS grade conversion) that is only partially related to walking (see above).

For prognostic purposes the T2 sagittal images seem to be the most useful ones, while $\mathrm{T} 1$ and axial images do not correlate with the prognosis (Bozzo et al., 2011). A damaged spinal cord exhibits a variable amount of intramedullary hemorrhage and edema. Both the presence of these two features and the amount of parenchyma that is affected by hemorrhage and edema are directly related to the degree of initial neurologic deficit and to the prognosis (Bondurant et al., 1990; Flanders et al., 1990). Based on these aspects, Bondurant and associates (Bondurant et al., 1990) proposed a classification which consider four different MRI patterns: Pattern 1 shows a normal MRI signal in the cord; pattern 2 represents single-level edema; pattern 3 is multi-level edema; and pattern 4 is mixed hemorrhage and edema.

Most studies showed that patients with spinal cord hemorrhage will have decreased motor power, lower motor recovery rates, and fewer muscles with useful function, 1 year after injury in comparison with subjects with small, non-hemorrhagic lesions (Bondurant et al., 1990; Flanders et al., 1990, 1996; Yamashita et al., 1991; Schaefer et al., 1992; Marciello et al., 1993; Sato et al., 1994; Ramón et al., 1997); hemorrhage on initial MRI (within 15 days from the lesion) is associated with a complete injury in almost $100 \%$ of the patients (Ramón et al., 1997). If no hemorrhage is seen on initial MRI, patients will have an incomplete lesion and have a significantly better prognosis for motor recovery in the upper and lower extremities, as well as improvement in their Frankel and/or ASIA impairment scale classification (Schaefer et al., 1992).

It is unclear whether the size of the hemorrhage is a prognostic feature. Some authors (Flanders et al., 1990; Schaefer et al., 1992; 
Table 4 | MRI and lesion severity.

\begin{tabular}{|c|c|}
\hline Authors & Results \\
\hline \multicolumn{2}{|c|}{ PRESENCE OF HEMORRHAGE AT INITIAL EXAMINATION } \\
\hline Marciello et al., 1993 & $\begin{array}{l}\text { Hemorrage = low upper extremity and no } \\
\text { lower extremity recovery }\end{array}$ \\
\hline Flanders et al., 1990 & $\begin{array}{l}\text { Hemorrage = decreased motor power, } \\
\text { lower motor recovery rate, and fewer } \\
\text { muscles with useful function }\end{array}$ \\
\hline Ramón et al., 1997 & Hemorrage $=$ complete injury \\
\hline \multicolumn{2}{|c|}{ SIZE OF HEMORRHAGE } \\
\hline $\begin{array}{l}\text { Boldin et al., 2006; } \\
\text { Flanders et al., 1990; } \\
\text { Schaefer et al., } 1992\end{array}$ & Small hemorrhage $=$ higher recovery rates \\
\hline $\begin{array}{l}\text { Bondurant et al., } \\
\text { 1990; } \\
\text { Flanders et al., } 1996\end{array}$ & $\begin{array}{l}\text { No relationship between hemorrhage size } \\
\text { and recovery }\end{array}$ \\
\hline \multicolumn{2}{|c|}{ PRESENCE OF EDEMA } \\
\hline Flanders et al., 1996 & $\begin{array}{l}\text { Edema }=\text { prognosis of recovery to } \\
\text { functional levels }(D / E)\end{array}$ \\
\hline Ramón et al., 1997 & $\begin{array}{l}\text { Edema }=\text { association with incomplete } \\
\text { syndromes }\end{array}$ \\
\hline \multicolumn{2}{|l|}{ SIZE OF EDEMA } \\
\hline $\begin{array}{l}\text { Flanders et al., 1990; } \\
\text { Flanders et al., 1996; } \\
\text { Ramón et al., } 1997\end{array}$ & $\begin{array}{l}\text { Degree of edema is inversely proportional } \\
\text { to initial impairment and future recovery }\end{array}$ \\
\hline $\begin{array}{l}\text { Boldin et al., 2006; } \\
\text { Flanders et al., } 1990\end{array}$ & $\begin{array}{l}\text { Multiple levels involvement }=\text { poorer } \\
\text { prognosis and greater chance of complete } \\
\text { lesions }\end{array}$ \\
\hline Flanders et al., 1996 & $\begin{array}{l}\text { Involvement of only one to three } \\
\text { segments }=\text { improved prognosis }\end{array}$ \\
\hline
\end{tabular}

Boldin et al., 2006) have shown that small hemorrhages may offer higher recovery rates; others showed no difference based on the size of the hemorrhage (Bondurant et al., 1990; Flanders et al., 1996).

With regard to spinal cord edema, this MRI finding seems to have a good prognostic value. In incomplete SCIs, the finding of edema in MRI is associated with a good prognosis of neurological recovery (Flanders et al., 1996). Furthermore, the incomplete syndromes, such as the Brown-Sèquard syndrome, seem to be associated with the edema pattern (Ramón et al., 1997). However, if the edema involves multiple levels, it tends to be associated with a poorer prognosis and a greater chance of having a complete lesion (Flanders et al., 1996; Boldin et al., 2006). If the cord edema is limited to one to three segments only, then the lesion is usually milder in nature, with an improved prognosis (Bauer and Errico, 1991).

Based on the classification of Bondurant et al. (1990), Bozzo et al. (2011) reviewed the data of several articles (Schaefer et al., 1992; Shimada and Tokioka, 1999; Andreoli et al., 2005) and found a correlation with the AIS conversion of patients. As already reported hemorrhage is the more severe MRI aspect, with about $95 \%$ of patients remaining with the same AIS grade of admission examination. Patients with diffuse edema also showed a poor improvement, as only $28 \%$ of them showed an improvement of AIS grade. Conversely, patients with single level edema pattern showed a good neurological outcome as $90 \%$ of them improved for a mean of 1.9 AIS grades.

Other positive correlations have been described: greater degree of cord compression, greater degree of canal compromise, and the severity of soft tissue injuries seem to be all associated with poorer neurological outcomes (Flanders et al., 1996; Selden et al., 1999; Dai and Jia, 2000; Miyanji et al., 2007; Song et al., 2008).

\section{TREATMENT}

In the last decade several interventions aiming at reducing the spinal cord damage (neuroprotection) have been proposed (Becker and McDonald, 2012). However, these interventions are still at an experimental level (Becker and McDonald, 2012). Therefore, in the following paragraphs we will focus only on the use and efficacy of high dose methylprednisolone (which, although questioned, is still the most widely used pharmacological treatment in the acute phase of SCI) and of early surgical intervention. It should be noticed that in both cases, studies referred to neurological improvement rather than to walking recovery. Therefore, data on the efficacy of these treatments on ambulation are not available.

\section{METHYLPREDNISOLONE}

The administration of high-dose methylprednisolone (MP) to patients with spinal cord injuries has been reported in the National Acute Spinal Cord Injury Studies (NASCIS, NASCISII, and NASCIS-III) (Bracken et al., 1984, 1990, 1997). Since then, the use of MP increased and became a standard of care for acute traumatic SCIs (Hurlbert, 2001). It has been hypothesized that MP attenuates the inflammatory cascade and lessens lipid peroxidation, thus decreasing secondary Spinal Cord damage (Delamarter et al., 1995). In the NASCIS studies, the 24 and $48 \mathrm{~h}$ administration of high dose MP produced an important neurologic recovery (AIS grade improvement) paralleled by a functional amelioration (Bracken et al., 1997). However, several recent revisions of NASCIS protocols and other randomized trials questioned the efficacy of steroids administration to achieve a neurologic improvement (Hurlbert, 2001; Matsumoto et al., 2001; Suberviola et al., 2008; Bydon et al., 2013). Furthermore, the 48-h-infusion of MP seems to be associated with an increased risk of pneumonia, sepsis, gastrointestinal bleeding, and steroid myopathy (Pointillart et al., 2000; Quian et al., 2004).

Based on these evidences, both the Consortium for Spinal Cord Medicine clinical practice guidelines (Consortium for Spinal Cord Medicine, 2007) and the neurosurgical guidelines (2002) consider the use of high-dose MP to be a treatment option rather than a standard.

\section{SURGERY TRIALS}

The undisputed benefits of surgical treatment for unstable vertebral injuries include decreased hospital stay, fewer sequelae from prolonged immobilization, and more rapid admission to the rehabilitation system (Raineteau and Schwab, 2001). 
Despite these evidence, the timing of decompression of the neural elements, and, in particular, the efficacy of early decompression (within $24 \mathrm{~h}$ ) in improving neurologic recovery is still a matter of debate (Fehlings and Tator, 1999; Fehlings and Perrin, 2005). A meta-analysis of studies of early decompression from 1966 through 2000 (La Rosa et al., 2004), showed that surgery performed within $24 \mathrm{~h}$ produced a significant improvement in neurological recovery compared with late surgery, but concluded that the evidence was not strong and that early surgery could be considered only as a practice option.

Starting from this framework, a recent prospective multicentric study (Fehlings et al., 2012) demonstrated that the odds of achieving a 2 AIS grade improvement is 2.8 times higher in patients undergoing early surgical decompression (within $24 \mathrm{~h}$ ). However, a recent meta-analysis (van Middendorp et al., 2013) reported a lack of statistical robustness of the articles examined, therefore the relationship between early surgery and better neurological outcome is still to be demonstrated.

\section{DISCUSSION}

This review demonstrates that the chance of walking recovery after a SCI can be accurately predicted on the base of demographic data and clinical examination. Patients with complete sensorymotor lesions have very limited possibility of achieving walking function at follow up, and also if they are able to ambulate they usually are "limited ambulators." The chances of walking recovery improve in less severe lesions, as demonstrated by AIS B and $\mathrm{C}$ subjects. AIS B patients can recover walking especially if their clinical picture shows a less severe involvement of the spinal cord (light touch and pinprick conservation = some sparing of the spino-thalamic and posterior columns tracts = higher possibility of cortico-spinal tracts preservation). Finally, subjects with AIS C lesions are bound to walk, especially the younger ones. This prognosis for walking may be sustained and empowered by instrumental examinations that help to assess the severity of the lesion and, in some cases (SSEPs and MEPs) are directly correlated with walking function.

The need to predict outcome based on expected neurological recovery and associated functional recovery has been emphasized as essential for health care planning (Ditunno, 1999) and this need is partially unmet.

During the first few days after SCI, definitive management strategies are formulated, which often include aggressive surgical decompression of the spinal cord (Wilson et al., 2012). This is also the time of greatest anguish for an injured patient and their family as they face significant prognostic uncertainty. A precise knowledge of the prognosis makes it possible to answer questions regarding function that patients usually ask after spinal cord injury: "Will I walk again?" and "What will I be able to do?" Furthermore, in countries with health care systems based on insurance, rehabilitation professionals have to justify and fight for appropriate services; furthermore they have to know how to allocate resources. Therefore, predicting recovery has become a rehabilitative imperative (Ditunno, 1999).

Finally, better knowledge of the course and prognosis of recovery after SCI and an understanding of the underlying mechanisms would help in the development of strategies and treatments to enhance neurological recovery. The number of interventions, therapies, and devices that have been developed and proposed to improve functional outcomes after SCI is enormous; several of these proposal will undergo clinical trials in the near future. Some early stage SCI clinical trials have recently been started and some experimental therapies have been introduced into clinical practice without a clinical trial being completed. Prognostic data are essential to evaluate the efficacy of new drugs and therapies (for example to distinguish between the natural recovery and the effect of treatments) and to project the clinical trials (for example to calculate the number of patients needed to obtain statistical power) (Fawcett et al., 2006).

\section{LIMITATIONS}

This article has several limitations due to the nature of the works examined. Some of them are based on small sample sizes and the definition of walking function and of follow up time points vary across the studies. Furthermore, these articles mainly represent the experience from USA and, in part, Europe. Therefore, they do not reflect the whole world standards of care. As SCI management may differ in different geographical areas, the rates of recovery of walking could vary to. Finally, the distribution in time of the works examined is not regular. Although the study of the prognostic factors is still a matter of interest, most of the articles related to clinical factors date back to the $80 \mathrm{~s}$ and $90 \mathrm{~s}$. Some prognostic factors may change over time as SCI management evolves. Based on these limitations the results of these studies could not be necessarily generalizable However, the factors that we examined here are still considered the base of the prognosis of SCI outcome (Burns et al., 2012).

\section{FUNDING}

Supported in part by grant RC12G of the Italian Ministry of Health and grant P133 of the International Foundation for Research in Paraplegia to Giorgio Scivoletto.

\section{REFERENCES}

(2002). Management of acute central cervical spinal cord injuries. Neurosurgery 50(3 Suppl.), S166-S172.

Aalfs, C. M., Koelman, J. H., Meyjes, F. E., and de Visser, B. W. O. (1993). Posterior tibial and sural nerve somatosensory evoked potentials: a study in spastic paraparesis in spinal cord lesions. Electroencephalogr. Clin. Neurophysiol. 89, 437-441. doi: 10.1016/0168-5597(93) 90118-9

Aito, S., D’Andrea, M., Werhagen, L., Farsetti, L., Cappelli, S., Bandini, B., et al. (2006). Neurological and functional outcome in traumatic central cord syndrome. Spinal Cord 45, 292-297. doi: 10.1038/sj.sc.3101944

American Spinal Injury Association. (2000). International standards for neurological classifications of spinal cord Injury (revised). Chicago, IL: American Spinal Injury Association.

Andreoli, C., Colaiacomo, M. C., Rojas Beccaglia, M., Di Biasi, C., Casciani, E., and Gualdi, G. (2005). MRI in the acute phase of spinal cord traumatic lesions: Relationship between MRI findings and neurological outcome. Radiol. Med. 110, 636-645.

Bauer, R. D., and Errico, T. J. (1991). “Cervical spine injuries,” in Spinal Trauma, eds T. J. Errico, R. D. Bauer, and T. Waugh (Philadelphia, PA: JB Lippincott), 71-121.

Becker, D., and McDonald, J. W. 3rd. (2012). Approaches to repairing the damaged spinal cord: overview. Handb. Clin. Neurol. 109, 445-461. doi: 10.1016/B978-0444-52137-8.00028-0 
Bohlman, H. H. (1979). Acute fractures and dislocations of the cervical spine. An analysis of three hundred hospitalized patients and review of the literature. $J$. Bone Joint Surg. Am. 61, 1119-1142.

Boldin, C., Raith, J., Fankhauser, F., Haunschmid, C., Schwantzer, G., and Schweighofer, F. (2006). Predicting neurologic recovery in cervical spinal cord injury with postoperative MR imaging. Spine 31, 554-559. doi: 10.1097/01.brs. 0000201274.59427.a4

Bondurant, F. J., Cotler, H. B., Kulkarni, M. V., McArdle, C. B., and Harris, J. H. (1990). Acute spinal cord injury: a study using physical examination and magnetic resonance imaging. Spine 15, 161-168. doi: 10.1097/00007632199003000-00002

Bozzo, A., Marcoux, J., Radhakrishna, M., Pelletier, J., and Goulet, B. (2011). The role of magnetic resonance imaging in the management of acute spinal cord injury. J. Neurotrauma 28, 1401-1411. doi: 10.1089/neu.2009.1236

Bracken, M. B., Collins, W. F., Freeman, D. F., Shepard, M. J., Wagner, F. W., Silten, R. M., et al. (1984). Efficacy of methylprednisolone in acute spinal cord injury. JAMA 251, 45-52. doi: 10.1001/jama.1984.03340250025015

Bracken, M. B., Shepard, M. J., Collins, W. F., Holford, T. R., Young, W., Baskin, D. S., et al. (1990). A randomized, controlled trial of methylprednisolone or naloxone in the treatment of acute spinal-cord injury. Results of the second national acute spinal cord injury study. N. Engl. J. Med. 322, 1405-1411. doi: 10.1056/NEJM199005173222001

Bracken, M. B., Shepard, M. J., Holford, T. R., Leo-Summers, L., Aldrich, E. F., Fazl, M., et al. (1997). Administration of methylprednisolone for 24 or 48 hours or tirilazad mesylate for 48 hours in the treatment of acute spinal cord injury. Results of the third national acute spinal cord injury randomized controlled trial. national acute spinal cord injury study. JAMA 277, 1597-1604. doi: 10.1001/jama.1997.03540440031029

Brown-Sequard, C. E. (1868). Lectures on the physiology and pathology of the central nervous system and the treatment of organic nervous affections. Lancet 2, 593-595, 659-662, 755-757, 821-823. doi: 10.1016/S0140-6736(02) 52465-X

Buchan, A. C., Fulford, G. E., Jellineck, E., Kerr, W. G., Newsam, J. E., and Stark, G. D. (1972). A preliminary survey of the incidence and etiology of spinal paralysis. Paraplegia 10, 23-28. doi: 10.1038/sc. 1972.5

Burns, A. S., Marino, R. J., Flanders, A. E., and Flett H. (2012). Clinical diagnosis and prognosis following spinal cord injury. Handb. Clin. Neurol. 109, 47-62. doi: 10.1016/B978-0-444-52137-8.00003-6

Burns, S. P., Golding, D. G., Rolle, W. A. Jr., Graziani, V., and Ditunno, J. F. (1997). Recovery of ambulation in motor incomplete tetraplegia. Arch. Phys. Med. Rehabil. 78, 1169-1172. doi: 10.1016/S0003-9993(97)90326-9

Bydon, M., Lin, J., Macki, M., Gokaslan, Z. L., and Bydon, A. (2013). The current role of steroids in acute spinal cord injury. World Neurosurg. doi: 10.1016/j.wneu.2013.02.062. [Epub ahead of print].

Celani, M. G., Spizzichino, L., Ricci, S., Zampolini, M., and Franceschini, M. (2001). Spinal cord injury in Italy: a multicenter retrospective study. Arch. Phys. Med. Rehab. 82, 589-596. doi: 10.1053/apmr.2001.21948

Chabot, R., York, D. H., Watts, C., and Waugh, W. A. (1985). Somatosensory evoked potentials evaluated in normal subjects in spinal cord injured patients. J. Neurosurg. 63, 544-551. doi: 10.3171/jns.1985.63.4.0544

Cheshire, W. E., Santos, C. C., Massey, E. W., and Howard, J. E. (1996). Spinal cord infarction: etiology and outcome. Neurology 47, 321-330. doi: 10.1212/WNL.47.2.321

Citterio, A., Franceschini, M., Spizzichino, L., Reggio, A., Rossi, B., and Stampacchia G. (2004). Nontraumatic spinal cord injury: an Italian survey. Arch. Phys. Med. Rehabil. 85, 1483-1487. doi: 10.1016/j.apmr.2003.09.028

Consortium for Spinal Cord Medicine. (2007). Early Acute Management in Adults with Spinal Cord Injury: a Clinical Practice Guideline for Health-Care Providers. Washington, DC: Paralyzed Veterans of America.

Crozier, K. S., Cheng, L. L., Graziani, V., Zorn, G., Herbison, G., and Ditunno, J. F. Jr. (1992). Spinal cord injury: prognosis for ambulation based on quadriceps recovery. Paraplegia 30, 762-767. doi: 10.1038/sc.1992.147

Crozier, K. S., Graziani, V., Ditunno, J. F. Jr., and Herbison, G. J. (1991). Spinal cord injury: prognosis for ambulation based on sensory examination in patients who are initially motor complete. Arch. Phys. Med. Rehabil. 72, 119-121.

Curt, A., and Dietz V. (1997). Ambulatory capacity in spinal cord injury: significance of somatosensory evoked potentials and ASIA protocols in predicting outcome. Arch. Phys. Med. Rehabil. 78, 39-43. doi: 10.1016/S0003-9993(97) 90007-1
Curt, A., Keck, M. E., and Dietz, V. (1998). Functional outcome following spinal cord injury: significance of motor-evoked potentials and ASIA scores. Arch. Phys. Med. Rehabil. 79, 81-86. doi: 10.1016/S0003-9993(98)90213-1

Dai, L., and Jia, L. (2000). Central cord injury complicating acute cervical disc herniation in trauma. Spine 25, 331-335. doi: 10.1097/00007632-200002010-00012

Delamarter, R. B., Sherman, J., and Carr, J. B. (1995). Pathophysiology of spinal cord injury: recovery after immediate and delayed compression. J. Bone Joint Surg. Am. 77, 1042-1049.

DiGiovanna, A. G. (2000). Human Ageing: Biological Perspectives, 2nd Edn. New York, NY: McGraw Hill Companies.

Ditunno, J. F. (1999). The John Stanley Coulter Lecture. Predicting recovery after spinal cord injury: a rehabilitation imperative. Arch. Phys. Med. Rehabil. 80, 361-364.

Ditunno, J. F., Scivoletto, G., Patrick, M., Biering-Sorensen, F., Abel, R., and Marino, R. (2008b). Validation of the walking index for spinal cord injury in a US and European clinical population. Spinal Cord 46, 181-188. doi: 10.1038/sj.sc.3102071

Ditunno, P. L., Patrick, M., Stineman, M., and Ditunno, J. F. (2008a). Who wants to walk? Preferences for recovery after SCI: a longitudinal and cross-sectional study. Spinal Cord. 46, 500-506. doi: 10.1038/sj.sc.3102172

Domingo, A., Al-Yahya, A. A., Asiri, Y., Eng, J. J., Tania Lam, T., and Spinal Cord Injury Rehabilitation Evidence Research Team. (2012). A systematic review of the effects of pharmacological agents on walking function in people with spinal cord injury. J. Neurotrauma 29, 865-879. doi: 10.1089/neu.2011.2052

Dvorak, M. F., Fisher, C. G., Hoekema, J., Boyd, M., Noonan, V., Wing, P. C., et al. (2005). Factors Predicting motor recovery and functional outcome after traumatic central cord syndrome a long-term follow-up. Spine 30, 2303-2311. doi: 10.1097/01.brs.0000182304.35949.11

Fawcett, J. W., Curt, A., Steeves, J. D., Coleman, W. P., Tuszynski, M. H., Lammertse, D., et al. (2006). Guidelines for the conduct of clinical trials for spinal cord injury as developed by the ICCP panel: spontaneous recovery after spinal cord injury and statistical power needed for therapeutic clinical trials. Spinal Cord 45, 190-205. doi: 10.1038/sj.sc.3102007

Fehlings, M. G., and Perrin, R. G. (2005). The role and timing of early decompression for cervical spine injury: update with a review of the recent clinical evidence. Injury 36(Suppl. 2), B13-B26. doi: 10.1016/j.injury.2005.06.011

Fehlings, M. G., and Tator, C. H. (1999). An evidence-based review of decompressive surgery in acute spinal cord injury: rationale, indications, and timing based on experimental and clinical studies. J. Neurosurg. Spine 91, 1-11. doi: 10.3171/spi.1999.91.1.0001

Fehlings, M. G., Vaccaro, A., Wilson, J. R., Singh, A. W., Cadotte, D., Harrop, J. S., et al. (2012). Early versus delayed decompression for traumatic cervical spinal cord injury: results of the Surgical Timing in Acute Spinal Cord Injury Study (STASCIS). PLoS ONE 7:e32037. doi: 10.1371/journal.pone.0032037

Flanders, A. E., Schaefer, D. M., Doan, H. T., Mishkin, M. M., Gonzalez, C. F., Northrup, B. E. (1990). Acute cervical spine trauma: correlation of MR imaging findings with degree of neurologic deficit. Radiology 177, 25-33.

Flanders, A. E., Spettell, C. M., Tartaglino, L. M., Friedman, D. P., and Herbison, G. J. (1996). Forecasting motor recovery after cervical spinal cord injury: value of MR imaging. Radiology 201, 649-655.

Foo, D. (1986). Spinal cord injury in forty-four patients with cervical spondylosis. Paraplegia 24, 301-306. doi: 10.1038/sc.1986.42

Foo, D., Subrahmanyan, T. S., and Rossier, A. B. (1981). Post-traumatic acute anterior spinal cord syndrome. Paraplegia. 19, 201-205. doi: 10.1038/sc.1981.42

Gentleman, D., and Harrington, M. (1984). Penetrating injury of the spinal cord. Injury 16, 7-8. doi: 10.1016/0020-1383(84)90101-3

Greenwald, B. D., Seel, R. T., Cifu, D. X., and Shah, A. N. (2001). Gender-related differences in acute rehabilitation lengths of stay, charges, and functional outcomes for a matched sample with spinal cord injury: a multicenter investigation. Arch. Phys. Med. Rehabil. 82, 1181-1187. doi: 10.1053/apmr.2001.24891

Herbison, G. J., Zerby, S. A., Cohen, M. E., Marino, R. J., and Ditunno, J. E. (1991). Motor power difference within the first two weeks post-SCI in cervical spinal cord quadriplegic subjects. J. Neurotrauma 9, 373-380. doi: 10.1089/neu.1992.9.373

Hurlbert, R. J. (2001). The role of steroids in acute spinal cord injury. An evidence-based analysis. Spine 26, S39-S46. doi: 10.1097/00007632-20011215100009

Hussey, R. W., and Stauffer, E. S. (1973). Spinal cord injury: requirements for ambulation. Arch. Phys. Med. Rehabil. 54, 544-547. 
Jacobs, S. R., Yeaney, N. K., Herbison, G. J., and Ditunno, J. F. Jr. (1995). Future ambulation prognosis as predicted by somatosensory evoked potentials in motor complete and incomplete quadriplegia. Arch. Phys. Med. Rehabil. 76, 635-641. doi: 10.1016/S0003-9993(95)80632-6

Jakob, W., Wirz, M., van Hedel, H. J., Dietz, V., and EM-SCI Study Group. (2009). Difficulty of elderly SCI subjects to translate motor recovery-"body function"-into daily living activities. J. Neurotrauma 26, 2037-2044. doi: 10.1089/neu.2008.0824

Kaplan, B. J., Friedman, W. A., and Gavenstein, D. (1985). Somatosensory evoked potential in hysterical paraplegia. Surg. Neurol. 23, 502-506. doi: 10.1016/00903019(85)90246-0

Kaplan, P. E., and Rosen, J. S. (1981). Somatosensory evoked potentials in spinal cord injured patients. Paraplegia 19, 118-122. doi: 10.1038/sc.1981.26

Katoh, S., and el Masry, W. S. (1995). Motor recovery of patients presenting with motor paralysis and sensory sparing following cervical spinal cord injuries. Paraplegia 33, 506-509.

Katz, R. T., Tolkeikis, R. J., and Knuth, A. E. (1991). Somatosensory-evoked and dermatomal-evoked potentials are not clinically useful in the prognostication of acute spinal cord injury. Spine 16, 730-735. doi: 10.1097/00007632-19910700000007

Kirshblum, S. C., and O'Connor, K. C. (1998). Predicting neurologic recovery in traumatic cervical spinal cord injury. Arch. Phys. Med. Rehabil. 79, 1456-1466.

Ko, H-Y., Ditunno, J. F., Graziani, V., and Little, J. W. (1999). The pattern of reflex recovery during spinal shock. Spinal Cord 37, 402-409. doi: 10.1038/sj.sc.3100840

La Rosa, G., Conti, A., Cardali, S., Cacciola, F., and Tomasello F. (2004). Does early decompression improve neurological outcome of spinal cord injured patients? Appraisal of the literature using a meta-analytical approach. Spinal Cord 42, 503-512. doi: 10.1038/sj.sc.3101627

Marciello, M., Flanders, A. E., Herbison, G. J., Schaefer, D. M., Friedman, D. P., and Lane, J. I. (1993). Magnetic resonance imaging related to neurologic outcome in cervical spinal cord injury. Arch. Phys. Med. Rehabil. 74, 940-946.

Marinho, A. R., Flett, H. M., Craven, C., Ottensmeyer, C. A., Parsons, D., and Verrier, M. C. (2012). Walking-related outcomes for individuals with traumatic and non-traumatic spinal cord injury inform physical therapy practice. J. Spinal Cord Med. 35, 371-381. doi: 10.1179/2045772312Y.00000 00038

Matsumoto, T., Tamaki, T., Kawakami, M., Yoshida, M., Ando, M., and Yamada, H. (2001). Early complications of high-dose methylprednisolone sodium succinate treatment in the follow-up of acute cervical spinal cord injury. Spine 26, 426-430. doi: 10.1097/00007632-200102150-00020

Maynard, F. M., Glen, G. R., Fountain, S., Wilmot, C., and Hamilton R. (1979). Neurological prognosis after traumatic quadriplegia. J. Neurosurg. 50, 611-616. doi: 10.3171/jns.1979.50.5.0611

Maynard, F. M. Jr., Bracken, M. B., Creasey, G., Ditunno, J. F. Jr., Donovan, W. H., Ducker, T. B., et al. (1997). International standards for neurological and functional classification of spinal cord injury patients (revised). Spinal Cord 35, 266-274. doi: 10.1038/sj.sc.3100432

McKinley, W., Santos, K., Meade, M., and Brooke, K. (2007). Incidence and outcomes of spinal cord injury clinical syndromes. J. Spinal Cord Med. 30, 215-224.

McKinley, W. O., Huang, M. E., and Tewksbury, M. A. (2000). Neoplastic vs. traumatic spinal cord injury: an inpatient rehabilitation comparison. Am. J. Phys. Med. Rehabil. 79, 138-144. doi: 10.1097/00002060-200003000-00005

McKinley, W. O., Seel, R. T., Gadi, R. K., and Tewksbury, M. A. (2001). Nontraumatic vs. traumatic spinal cord injury. Am. J. Phys. Med. Rehab. 80, 693-699. doi: 10.1097/00002060-200109000-00010

Mckinley, W. O., Tewksbury, M. A., and Mujteba, N. M. (2002). Spinal stenosis vs traumatic spinal cord injury: a rehabilitation outcome comparison. J. Spinal Cord Med. 25, 28-32.

Merriam, W. E., Taylor, T. K. F., Ruff, S. J., and McPhail, M. J. (1986). A reappraisal of acute traumatic central cord syndrome. J. Bone Joint Surg. 68B, 708-713.

Miyanji, F., Furlan, J. C., Aarabi, B., Arnold, P. M., and Fehlings, M. G. (2007). Acute cervical traumatic spinal cord injury: MR imaging findings correlated with neurologic outcome-prospective study with 100 consecutive patients. Radiology 243, 820-827. doi: 10.1148/radiol.2433060583

Newey, M. L., Sen, P. K., and Fraser, R. D. (2000). The long-term outcome after central cord syndrome: a study of the natural history. J. Bone Joint Surg. Br. 82, 851-855. doi: 10.1302/0301-620X.82B6.9866
Oleson, C. V., Burns, A. S., Ditunno, J. F., Geisler, F. H., and Coleman, W. P. (2005). Prognostic value of pinprick preservation in motor complete, sensory incomplete spinal cord injury. Arch. Phys. Med. Rehabil. 86, 988-992. doi: 10.1016/j.apmr.2004.09.031

Pagliacci, M. C., Celani, M. G., Spizzichino, L., Zampolini, M., Aito, S., Citterio, A., et al. (2003).Gruppo Italiano Studio Epidemiologico Mielolesioni (GISEM) Group. spinal cord lesion management in Italy: a 2-year survey. Spinal Cord 41, 620-628. doi: 10.1038/sj.sc.3101521

Penrod, L. E., Hegde, S. K., and Ditunno, J. E. (1990). Age effect on prognosis for functional recovery in acute, traumatic central cord syndrome. Arch. Phys. Med. Rehabil. 71, 963-968.

Perot, P. L., and Vera, C. L. (1982). Scalp-recorded somatosensory evoked potentials to stimulation of nerves in the lower extremities and evaluation of patients with spinal cord trauma. Ann. N.Y. Acad. Sci. 388, 359-368. doi: 10.1111/j.17496632.1982.tb50802.x

Pointillart, V., Petitjean, M. E., Wiart, L., Vital, J. M., Lassie, P., Thicoipe, M., et al. (2000). Pharmacological therapy of spinal cord injury during the acute phase. Spinal Cord 38, 71-76. doi: 10.1038/sj.sc.3100962

Quian, T., Guo, X., Levi, A. D., Vanni, S., Shebert, R. T., and Sipski, M. L. (2004). High-dose methylprednisolone may cause myopathy in acute spinal cord injury patients. Spinal Cord 43, 199-203. doi: 10.1038/sj.sc.3101681

Raineteau, O., and Schwab, M. E. (2001). Plasticity of motor systems after incomplete spinal cord injury. Nat. Rev. Neurosci. 2, 263-273. doi: 10.1038/35067570

Ramón, S., Domínguez, R., Ramírez, L., Paraira, M., Olona, M., Castelló, T., et al. (1997). Clinical and magnetic resonance imaging correlation in acute spinal cord injury. Spinal Cord 35, 664-673. doi: 10.1038/sj.sc.3100490

Roth, E. J., Lawler, M. H., and Yarkony, G. M. (1990). Traumatic central cord syndrome: clinical features and functional outcomes. Arch. Phys. Med. Rehabil. 71, $18-23$.

Roth, E. J., Park, T., Pang, T., Yarkony, G. M., and Lee, M. Y. (1991). Traumatic cervical Brown-Sequard and Brown-Sequard plus syndromes: the spectrum of presentations and outcomes. Paraplegia 29, 582-589. doi: 10.1038/sc.1991.86

Sato, T., Kokubun, S., Rijal, K. P., Ojima, T., Moriai, N., Hashimoto, M., et al. (1994). Prognosis of cervical spinal cord injury in correlation with magnetic resonance imaging. Paraplegia 32, 81-85. doi: 10.1038/sc.1994.14

Schaefer, D. M., Flanders, A. E., Osterholm, J. L., and Northrup, B. E. (1992). Prognostic significance of magnetic resonance imaging in the acute phase of cervical spine injury. J. Neurosurg. 76, 218-223. doi: 10.3171/jns.1992.76.2.0218

Scivoletto, G., Farchi, S., Laurenza, L., and Molinari, M. (2011). Traumatic and non-traumatic spinal cord lesions: an Italian comparison of neurological and functional outcomes. Spinal Cord 49, 391-396. doi: 10.1038/sc.2010.85

Scivoletto, G., Morganti, B., Ditunno, P., Ditunno, J. F., and Molinari, M. (2003). Effects on age on spinal cord lesion patients' rehabilitation. Spinal Cord 41 457-464. doi: 10.1038/sj.sc.3101489

Scivoletto, G., Morganti, B., and Molinari, M. (2004a). Neurologic recovery of spinal cord injury patients in Italy. Arch. Phys. Med. Rehabil. 85, 485-489. doi: 10.1016/S0003-9993(03)00766-4

Scivoletto G., Morganti B., and Molinari, M. (2004b). Sex-related differences of rehabilitation outcomes of spinal cord lesion patients. Clin. Rehabil. 18, 709-713. doi: 10.1191/0269215504cr749oa

Selden, N. R., Quint, D. J., Patel, N., D’Arcy, H. S., and Papadopoulos, S. M. (1999). Emergency magnetic resonance imaging of cervical spinal cord injuries: clinical correlation and prognosis. Neurosurgery 44, 785-792.

Shimada, K., and Tokioka, T. (1999). Sequential MR studies of cervical cord injury: correlation with neurological damage and clinical outcome. Spinal Cord 37, 410-415. doi: 10.1038/sj.sc.3100858

Sipski, M. L., Jackson, A. B., Gómez-Marín, O., Estores, I., and Stein, A. (2004) Effects of gender on neurologic and functional recovery after spinal cord injury. Arch. Phys. Med. Rehabil. 85, 1826-1836. doi: 10.1016/j.apmr.2004. 04.031

Song, K. J., Kim, G. H., and Lee, K. B. (2008). The efficacy of the modified classification system of soft tissue injury in extension injury of the lower cervical spine. Spine 33, E488-E493. doi: 10.1097/BRS.0b013e31817b6191

Stahlman, G. C., and Hanley, E. N. (1992). "Surgical management of spinal injuries," in Skeletal Trauma, eds B. D. Browner, J. B. Jupiter, A. M. Levine, and P. G. Trafton (Philadelphia: WB Saunders), 837-860.

Steeves, J. D., Lammertse, D., Curt, A., Fawcett, J. W., Tuszynski, M. H., Ditunno, J. F., et al. (2007). International campaign for cures of spinal cord injury paralysis. guidelines for the conduct of clinical trials for spinal cord injury (SCI) as 
developed by the ICCP panel: clinical trial outcome measures. Spinal Cord 45, 190-205. doi: 10.1038/sj.sc.3102008

Suberviola, B., Gonzalez-Castro, A., Llorca, J., Ortiz-Melon, F., and Minambres, E. (2008). Early complications of high-dose methylprednisolone in acute spinal cord injury patients. Injury 39, 748-752. doi: 10.1016/j.injury.2007.12.005

Vaccaro, A. R., Daugherty, R. J., Sheehan, T. P., Dante, S. J., Cotler, J. M., Balderston, R. A., et al. (1997). Neurologic outcome of early versus late surgery for cervical spinal cord injury. Spine 22, 2609-2613. doi: 10.1097/00007632-19971115000006

van Middendorp, J. J., Hosman, A. J., and Doi, S. A. (2013). The effects of the timing of spinal surgery after traumatic spinal cord injury: a systematic review and meta-analysis. J. Neurotrauma 30, 1781-1794. doi: 10.1089/neu.2013.2932

van Middendorp, J. J., Hosman, A. J., Donders, A. R., Pouw, M. H., Ditunno, J. F. Jr., Curt, A., et al. (2011). A clinical prediction rule for ambulation outcomes after traumatic spinal cord injury: a longitudinal cohort study. Lancet 377, 1004-1010. doi: 10.1016/S0140-6736(10)62276-3

van Middendorp, J. J., Hosman, A. J., Pouw, M. H., EM-SCI Study Group, and Van de Meent, H. (2009). ASIA impairment scale conversion in traumatic SCI: is it related with the ability to walk? A descriptive comparison with functional ambulation outcome measures in 273 patients. Spinal Cord 47, 555-560. doi: $10.1038 /$ sc. 2008.162

Waters, R. L., Adkins, R. H., Yakura, J. S., and Sie, I. (1994a). Motor and sensory recovery following incomplete tetraplegia. Arch. Phys. Med. Rehabil. 75, 306-311. doi: 10.1016/0003-9993(94)90034-5

Waters, R. L., Adkins, R. H., Yakura, J. S., and Sie, I. (1994b). Motor and sensory recovery following incomplete paraplegia. Arch. Phys. Med. Rehabil. 75, 67-72. doi: 10.1016/0003-9993(94)90034-5

Weinstein, D. E., Ko, H. Y., Graziani, V., and Ditunno, J. F. Jr. (1997). Prognostic significance of the delayed plantar reflex following spinal cord injury. Spinal Cord Med. 20, 207-211.

Wernig, A., and Muller, S. (1992). Laufband locomotion with body weight support improved walking in persons with severe spinal cord injuries. Paraplegia 30, 229-238. doi: 10.1038/sc.1992.61

Wilson, J. R., Grossman, R. G., Frankowski, R. F., Kiss, A., Davis, A. M., Kulkarni, A. V., et al. (2012). A clinical prediction model for long-term functional outcome after traumatic spinal cord injury based on acute clinical and imaging factors. J. Neurotrauma 29, 2263-2271. doi: 10.1089/neu.2012.2417

Yamashita, Y., Takahashi, M., Matsuno, Y., Kojima, R., Sakamoto, Y., Oguni, T., et al. (1991). Acute spinal cord injury: magnetic resonance imaging correlated with myelopathy. Br. J. Radiol. 64, 201-209. doi: 10.1259/0007-1285-64-759-201

Young, J. S., and Dexter, W. R. (1979). Neurological recovery distal to the zone of injury in 172 cases of closed, traumatic spinal cord injury. Paraplegia 16, 39-49. doi: $10.1038 /$ sc. 1978.6

Young, W. (1985). "Somatosensory evoked potentials (SEPs) in spinal cord injury," in Spinal Cord Monitoring, eds J. Schranml and S. J. Jones (Berlin: SpringerVerlag), 127-142.

Ziganow, S. (1986). Neurometric evaluation of the cortical somatosensory evoked potential in acute incomplete spinal cord injuries. Electroencephalogr. Clin. Neurophysiol. 65, 86-93. doi: 10.1016/0168-5597(86)90040-7

Zörner, B., Blanckenhorn, W. U., Dietz, V., EM-SCI Study Group, and Curt, A. (2010). Clinical algorithm for improved prediction of ambulation and patient stratification after incomplete spinal cord injury. J. Neurotrauma 27, 241-252. doi: 10.1089/neu.2009.0901

Conflict of Interest Statement: The authors declare that the research was conducted in the absence of any commercial or financial relationships that could be construed as a potential conflict of interest.

Received: 04 December 2013; accepted: 26 February 2014; published online: 13 March 2014.

Citation: Scivoletto G, Tamburella F, Laurenza L, Torre M and Molinari M (2014) Who is going to walk? A review of the factors influencing walking recovery after spinal cord injury. Front. Hum. Neurosci. 8:141. doi: 10.3389/fnhum.2014.00141

This article was submitted to the journal Frontiers in Human Neuroscience.

Copyright $\odot 2014$ Scivoletto, Tamburella, Laurenza, Torre and Molinari. This is an open-access article distributed under the terms of the Creative Commons Attribution License (CC BY). The use, distribution or reproduction in other forums is permitted, provided the original author(s) or licensor are credited and that the original publication in this journal is cited, in accordance with accepted academic practice. No use, distribution or reproduction is permitted which does not comply with these terms. 